See Article page 920.

\section{Commentary: Perceval sutureless valve - one more seat at the round table of short-term follow-up}

\author{
Stephen H. McKellar, MD, MSc
}

We congratulate Fischlein and coauthors ${ }^{1}$ for their article in this issue of the Journal reporting 1-year outcomes from a well-designed, randomized clinical trial of the Perceval Sutureless Implant Versus Standard-Aortic Valve Replacement (PERSIST-AVR) trial, an industry-sponsored trial that randomized $>900$ patients to either sutureless or stented bioprosthetic valves for aortic stenosis. The primary endpoint was noninferiority with respect to major adverse cardiovascular and cerebrovascular events of the Perceval valve compared with a stented prosthesis at 1 year. Secondary endpoints included morbidities such as perioperative complications, implantation of a permanent pacemaker (PPM), and valve function. They observed noninferiority of the sutureless valve compared with the stented prosthesis in both intent-to-treat and modified intent-to-treat analyses. For the secondary endpoint, most outcome measures were comparable except for an increased need for PPM in the sutureless valve group. The authors concluded that the sutureless aortic valve prosthesis is noninferior to stented prostheses with respect to major adverse cardiovascular and cerebrovascular events at 1 year.

The results of this positive trial add another option for clinicians who treat patients with aortic valve disease. In addition to mechanical prostheses, stented and stentless bioprosthesis, and transcatheter valves, there are now 2 rapid-deployment tissue prostheses with compelling short-term safety and efficacy data. Like transcatheter valves, these rapid-deployment surgical valves have a significantly increased risk of permanent pacemaker placement in exchange for shorter cardiopulmonary bypass and aortic cross-clamp times.

From the Division of Cardiovascular and Thoracic Surgery, Intermountain Medical Center, Murray, Utah.

Disclosures: The author reported no conflicts of interest.

The Journal policy requires editors and reviewers to disclose conflicts of interest and to decline handling or reviewing manuscripts for which they may have a conflict of interest. The editors and reviewers of this article have no conflicts of interest.

Received for publication Nov 20, 2020; revisions received Nov 20, 2020; accepted for publication Nov 20, 2020; available ahead of print Dec 3, 2020.

Address for reprints: Stephen H. McKellar, MD, MSc, Division of Cardiovascular and Thoracic Surgery, Intermountain Medical Center, Eccles Outpatient Center, 5169 Cottonwood St, Suite 600, Murray, UT 84107 (E-mail: stephen.mckellar@ imail.org).

J Thorac Cardiovasc Surg 2021;161:934

$0022-5223 / \$ 36.00$

Copyright (c) 2020 by The American Association for Thoracic Surgery

https://doi.org/10.1016/j.jtcvs.2020.11.133

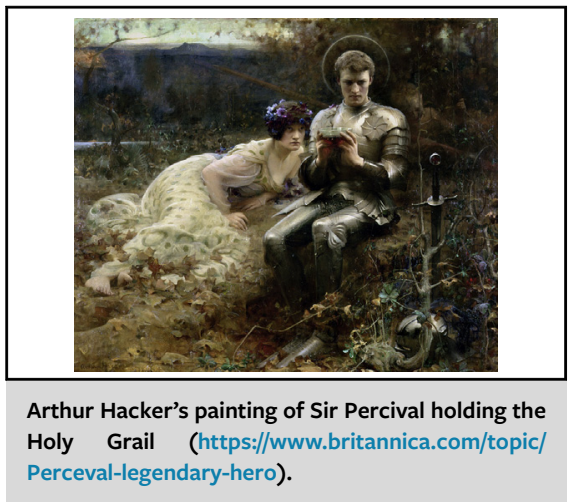

CENTRAL MESSAGE

Rapid-deployment surgical aortic

valve bioprostheses, like the

Perceval valve, add to clinicians'

options for treating patients with

aortic valve disease. Long-term

outcomes will define the dura-

bility of these prostheses.

The Perceval valve is named after the legendary knight in King Arthur's court, and with this study, it appears that the round table of options of valve substitutes is looking increasingly crowded. There is much that we know about surgical vs transcatheter approaches and now between conventional vs sutureless surgical techniques. But there is still much we don't know about nearly all the guests at the round tablelong-term durability. With only long-term durability data available on older, obsolete transcatheter valves and only short-term data available for newer transcatheter and rapiddeployment sutureless valves, only time will tell how these newer technologies compare with the well-established durability of stented and stentless bioprostheses.

Acknowledging the risk of forcing the Percival metaphor too far, another reference to Percival in King Arthur's court is as a seeker and defender of the Holy Grail. Is there a holy grail of aortic valve bioprostheses? As of right now, there does not appear to be a clear winner that balances procedural morbidity against long-term durability. Instead, what we now have are many good options to help clinicians tailor the best valve prosthesis for each patient's unique conditions and comorbidities.

\section{Reference}

1. Fischlein T, Folliguet T, Meuris B, Shrestha ML, Roselli EE, McGlothlin A, et al. Sutureless versus conventional bioprostheses for aortic valve replacement in severe symptomatic aortic valve stenosis. J Thorac Cardiovasc Surg. 2021;161: 920-32. 